\title{
EGIPTOMANIA NO CAMPO DOS BRINQUEDOS
}

Alice Alves Gomes Dierckx Orientação: Renata Senna Garraffoni

PALAVRAS-CHAVE: Egiptomania; apropriação de símbolos; construção símbólica dos brinquedos.

A pesquisa que se apresenta partiu de um desejo pessoal de me dedicar à fantástica sociedade do Nilo, porém, algumas dificuldades levaram a uma adaptação contemporânea a partir da obra Egitptomania $^{1}$ de Margaret Bakos. O universo vastíssimo de possibilidades e o crescimento constante de estudos do fenômeno da Egiptomania no Brasil permitiram definição do tema. A produção da monografia foi dividida em três capítulos a partir de grandes eixos, nos quais o primeiro é dedicado a questões teórico-metodológicas, o segundo a construção cultural que se produziu a respeito do Oriente e à temática da Egiptomania, o terceiro e último trata das fontes, do papel social dos brinquedos, em geral, e das bonecas em específico.

O estudo da Egiptomania, reutilização de símbolos egípcios com diferentes significados, pode ser entendida a partir História Cultural e muito ligada à questão do imaginário. Uma pesquisa histórica nesse sentido é possível a partir da mudança paradigmática da historiografia proporcionada pela Escola dos Annales. Esse movimento historiográfico fundado por March Bloch e Lucien Febvre em 1929 e que reuniu nomes como Georges Duby, Michael Foucault e Jacques Le Goff, defende a interdisciplinaridade no campo de estudo da História, principalmente com Arqueologia, Sociologia, Geografia entre outras. Em sua $3^{a}$ geração, conhecida como a "Nova História", insere todos os aspectos da vida cotidiana como objeto de estudo do historiador. Cabe aos Annales ainda a percepção de que a produção da História é, antes de tudo, um discurso, carregado de subjetividades e concepções pessoais do historiador, distante dos

${ }^{1}$ BAKOS, M. Egiptomania: o Egito no Brasil. São Paulo: Paris Editorial, 2009. 
ideais de neutralidade e verdade por tanto tempo defendidos. O historiador reflete sua intencionalidade desde a escolha de suas fontes até a conclusão final de seu trabalho, passando pela metodologia empregada. Nesse sentido, esse trabalho não busca a produção de um discurso detentor da verdade, mas se baseia em uma escolha consciente das fontes, das abordagens, dos autores e, principalmente, de sua subjetividade.

Por se tratar de um tema estudado apenas recentemente no Brasil, as reflexões acerca da apropriação de símbolos egípcios produzidas pelo grupo de estudos Egiptomania organizado pela Prof ${ }^{a}$ Dr ${ }^{\mathrm{a}}$ Margaret Bakos na PUC-RS, nortearam algumas das escolhas para esse trabalho. O Antigo Egito exerce fascínio sobre a humanidade desde tempos muito remotos até os dias atuais, presente ainda na Idade Média e, posteriormente, no período napoleônico. Esse fascínio pelo Egito intensificou-se com as descobertas realizadas pela expedição enviada por Napoleão Bonaparte ao território egípcio no século XVIII. Dentre as mais importantes descobertas destaca-se a Pedra da Roseta, pedra triangular contendo inscrições de um mesmo texto em escrita grega, demótica ${ }^{2}$ e hieroglífica. Com isso, em 1821, Jean-François Champollion fez a primeira leitura de hieróglifos, criando a possibilidade de se estudar o passado egípcio a partir de textos da época, aumentando o interesse pelo Egito.

Segundo Bakos, há três formas de classificar esse interesse: a Egiptofilia, caracterizada pelo gosto por objetos, pelo exotismo e pela arquitetura egípcios; a Egiptologia, que consiste no estudo científico de todo o que é relativo ao Egito; e a Egiptomania, ou Revivificação Egípcia, Estilo do Nilo ou ainda Faraonismo, que é a apropriação de traços da cultura egípcia com interpretações atuais por diferentes culturas, por exemplo, a utilização de símbolos como a pirâmide em $\operatorname{logotipos}^{3}$. A prática da Egiptofilia é anterior à Egiptologia, por exemplo, há um episódio marcante no qual o imperador romano Augusto ordena o envio de obeliscos e monumentos egípcios para

${ }^{2}$ Escrita egípcia cursiva variante da escrita hieroglífica;

${ }^{3}$ BAKOS, op. cit., pp. 10-11. 
Roma ainda na Antiguidade. A Egiptologia ganha forças nos séculos XIX e XX com a já citada leitura dos hieróglifos e a crescente descoberta de túmulos como o de Tutankhamon em 1922. Apesar de não ser tão evidente quanto a Egiptofilia, a Egiptomania é um fenômeno muito presente no cotidiano das cidades, nas ruas e até nas residências. Vivemos cercados por símbolos referentes à civilização egípcia, da arquitetura à publicidade. Como ressalta Margaret Bakos ${ }^{4}$, é preciso recorrer à Egiptologia para tratar da Egiptomania uma vez que esta tem origem na junção entre ciência- estudos acadêmicos- e imaginação, misticismo.

A Egiptomania foi introduzida no Brasil por D. Pedro I que reuniu um acervo considerável de peças egípcias e foi fortalecida por D Pedro II que se tornou um estudioso da cultura egípcia, chegando a visitar o Egito em duas ocasiões. Em sua obra, Margaret Bakos ressalta as dificuldades encontradas ao realizar a pesquisa sobre Egiptomania no Brasil, uma vez que não havia publicações anteriores, foi necessária uma pesquisa de âmbito nacional para levantar dados, seguindo modelos de pesquisas européias. Nesse sentido, o interesse pelo tema para a pesquisa que se apresenta, se deu devido ao fato de que o estudo do fenômeno ainda é pouco difundido no Brasil, mesmo sendo um tema muito interessante.

Segundo Raquel Funari ${ }^{5}$, a Egiptomania não se restringe a uma "mania” pelo Egito, não é apenas uma cópia das formas egípcias, estas adquirem novos significados no contexto da época em que são criadas. É exatamente isso que se pretendeu estudar a por meio dessa pesquisa, para tal serão utilizadas como fontes duas bonecas BarbieCleópatra e Princesa do Nilo, um brinquedo da empresa Faber Castell - Múmias do Egito e uma boneca Susie- Rainha do Nilo -, todos exemplos de apropriação da simbologia egípcia. A escolha das fontes se deu a partir de sugestão do professor Moacir Elias Santos, por

\footnotetext{
${ }^{4}$ Idem, ibidem

${ }^{5}$ FUNARI, R. dos Santos. As imagens sobre o Egito à luz das discussões recentes. Revista dos estudos filosóficos e históricos da antiguidade. N 20/21. CPA-IFCHUNICAMP-SP.
} 
estarem disponíveis na internet e por serem fontes inéditas para esse tipo de estudo. A escolha dos brinquedos em geral, possibilita o estudo do universo da brincadeira, presente na humanidade desde tempos remotos, e do papel social desses objetos. As bonecas, em específico, permitem compreender como esse fenômeno se relaciona com o imaginário feminino, não só infantil, relacionado à imagem principalmente de Cleópatra e da deusa Ísis.

Como a Egiptomania é uma junção de ciências e imaginação, dos conhecimentos acadêmicos sobre o antigo Egito, com a sabedoria popular dos mitos e símbolos, ambos traços do Orientalismo, se faz necessário um diálogo com autores que tratam do imaginário no campo da História. As representações de uma sociedade são parte de um sistema que se articula com todos os outros, como religião e modos de comunicação, como defende Evelyne Platagean ${ }^{6}$. Cabe ao historiador estudar a importância do imaginário nessa contínua relação entre os sistemas e, segundo Jacques Le Goff ${ }^{7}$, por ser ofício a história, é preciso criar métodos e propor uma reflexão sobre estes temas. Nesse sentido, se faz importante relacionar o estudo do imaginário e dos usos que o historiador faz do passado, ou seja, como o presente se relaciona com esse passado.

Os debates historiográficos desde a década de 1990, têm buscado interpretações mais plurais e heterogêneas a cerca do passado, fugindo de grandes modelos normativos de interpretação. Conforme afirma Glaydson José da Silva : "Parece haver uma espécie de vontade mais de compreender do que de explicar (...)”. Nesse sentido, o autor defende que a ausência de uma tradição clássica relativa ao passado clássico, tema de suas pesquisas - contribuiu para que a historiografia brasileira não fosse carregada de valores

\footnotetext{
${ }^{6}$ PLATAGEAN, E. A história do imaginário. In: LE GOFF, J. A história nova. São Paulo: Martins Fontes, 2001, p. 309.

${ }^{7}$ LE GOFF, J. A história nova. São Paulo: Martins Fontes, 2001, p. 05.

${ }^{8}$ SILVA, G. J. Antigüidade, Arqueologia e a França de Vichy: usos do passado, 2005. Tese (Doutorado em História) - Instituto de Filosofia, e Ciências Humanas, Universidade Estadual de Campinas, 2005, pp. 27-28.
} 
nacionais e de identidade, como acontece com a historiografia européia. Durante o processo de desenvolvimento da história problema, o "presentismo" se tornou uma conseqüência incômoda, mas a qual não se podia negar a existência. A História produz um discurso sobre o passado, que representa a visão de mundo contemporânea de quem o escreve, é essencial ao estudar o passado, pensar as tradições interpretativas dessa História. A intencionalidade da produção historiográfica em cada período está intimamente ligada a questões contemporâneas, como política, busca por legitimidade social, entre outras.

O estudo da Egiptomania não está isento destes aspectos, pois envolve imaginário e ciência e, conforme Raquel Funari ${ }^{9}$, nenhum gênero escapou dessa influência. Nesse sentido, é importante compreender como a publicidade e o marketing sofreram essa influência. Segundo Margaret Bakos, Márcia Raquel Brito, Marcelo Chechelski e Flávia Dexheimer ${ }^{10}$, "publicitários, proprietários de estabelecimentos comerciais e fabricantes de produtos, quando decidem utilizar elementos egípcios na divulgação de seus negócios, o fazem, na maioria dos casos, baseados em uma escolha refletida", geralmente associada a noções como grandeza e sabedoria, entre outras ligadas às pirâmides e outros elementos egípcios.

Assim, é necessário compreender o imaginário que se faz presente nas fontes dessa pesquisa, as bonecas e os brinquedos.

\footnotetext{
${ }^{9}$ FUNARI, op.cit., p. 203-204.

${ }^{10}$ BAKOS, M., BRITO, M.R., CHECHELSKI M., DEXHEIMER, F.M. Marketing e Egito In: BAKOS, M. Egiptomania..., p. 135.
} 
Revista Vernáculo, n. 23 e 24, 2009

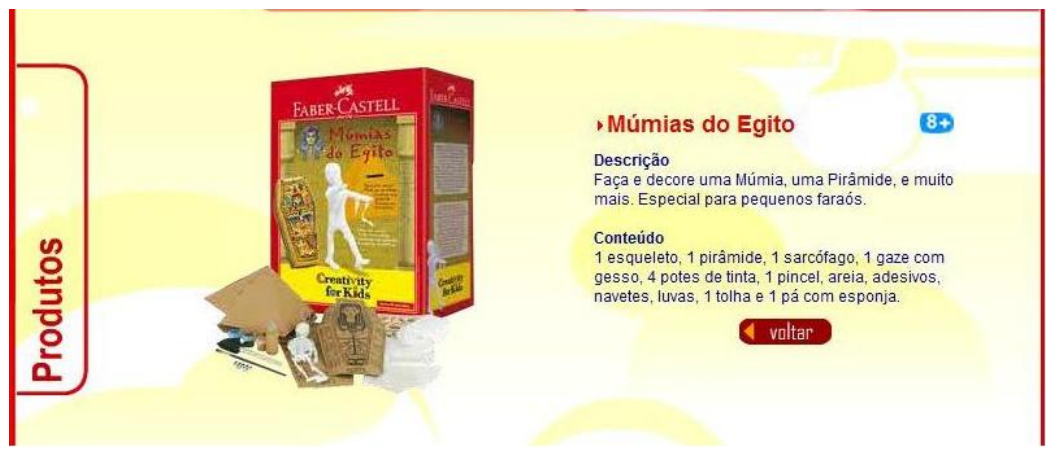

“Múmias do Egito” - Faber-Castell

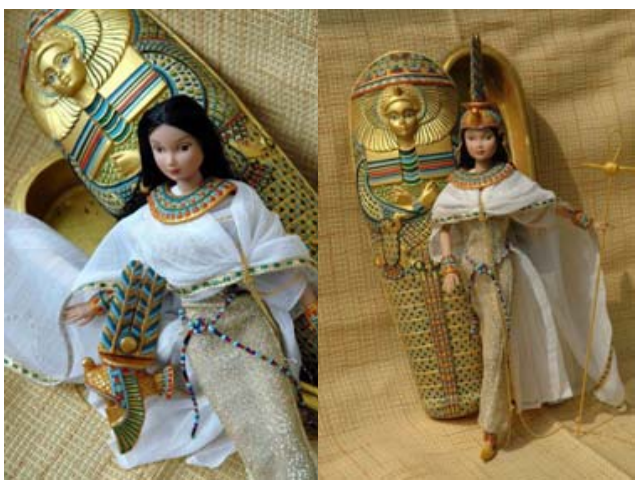

Susie "Queen of Nile”

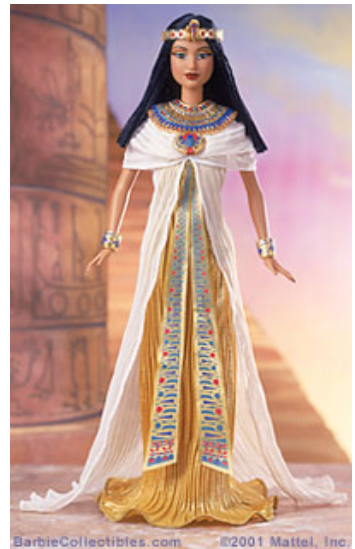

Barbie "Princess of Nile"

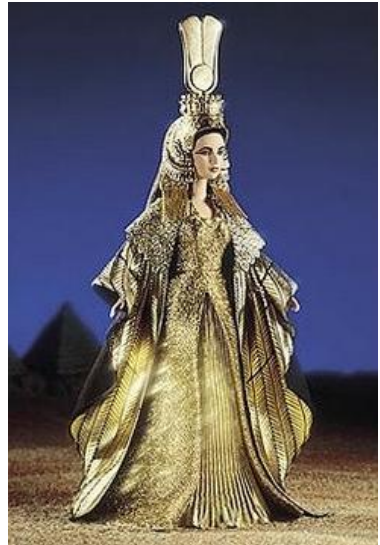

Barbie "Cleópara - Elizabeth Taylor" 
Os brinquedos possuem um papel social importantíssimo desde tempos muito remotos, pois a relação das crianças com o mundo passa pelo universo da brincadeira, que algumas vezes acaba reproduzindo situações reais e cotidianas - como o caso das brincadeiras com bonecas. É durante a infância que imagens e representações são apropriadas pela criança, seja através dos jogos, dos brinquedos, dos filmes e quadrinhos, dos conhecimentos de sala de aula ou dos assuntos discutidos em casa como defendido por Raquel Funari ${ }^{11}$. O papel social dos brinquedos está diretamente ligado à formação cultural dessas crianças, sofrendo variações históricas e culturais. Nesse sentido, o brinquedo é um produto de uma determinada sociedade, logo é carregado de seus traços culturais, fazendo parte do sistema dessa sociedade. Segundo Viviam Carvalho de Araújo ${ }^{12}$ : "O brinquedo está inserido em um sistema social e é portador de funções sociais e de significados que remetem a elementos do real e do imaginário das crianças.” A cultura lúdica está intimamente ligada ao universo cultural em que essa criança está envolvida, em que a mídia muitas vezes tem papel fundamental. Nesse sentido, os filmes, jogos e desenhos são apropriados através das brincadeiras, enriquecendo-as e trazendo novas relações entre a cultura infantil e os brinquedos. É essencial compreender a relação das crianças com esses brinquedos no ato do brincar, e o desenvolvimento desse importante elemento cultural.

As bonecas Barbie, e sua semelhante Susie, segundo Andréa Versutt ${ }^{13}$ fazem parte de um imaginário muito ligado à "realização dos sonhos, a projeção dos papéis sociais e valores positivados". Nesse sentido, a Barbie foi sendo modificada, adquirindo novas roupas, penteados e profissões de acordo com as tendências do

\footnotetext{
${ }^{11}$ FUNARI, R. S. Imagens do Egito Antigo: um estudo de representações históricas. São Paulo: Annablume, 2006.

12 ARAÚJO, V. C. Reflexões sobre o brincar infantil. Revista Educação em Destaque. Colégio Militar de Juiz de Fora, edição 1, vol. 1, 2008.

${ }^{13}$ VERSUTTI, A. Eu tenho, você não tem: o discurso publicitário infantil e a motivação ao consumo. Campinas: Unicamp, 2000, p. 147.
} 
universo feminino idealizado e, também, foi incorporando estrelas do cinema, como é o caso da Barbie Cleópatra, reprodução da personagem de Elizabeth Taylor. Para compreender esse "ideal" em torno dos brinquedos em geral, é preciso inseri-los no contexto de uma "mundialização" cultural do século XX.

A confecção dos brinquedos foi, durante muito tempo, caseira e artesanal, com materiais muito distintos daqueles utilizados atualmente, como cerâmica, madeira e tecidos. Gradativamente a produção dos brinquedos foi acompanhando a mundialização cultural, processo decorrente de uma "segunda industrialização" segundo Edgar Morin ${ }^{14}$ iniciada no início do século XX que criou padrões culturais e de consumo que se expandiram pelo mundo. Os brinquedos, importantes elementos culturais estão muito ligados a certos traços da sociedade atual. Pode-se facilmente notar a questão de gênero implícita no universo dos brinquedos, há brinquedos para meninas e brinquedos para meninos, e essa diferenciação está enraizada naquilo que se espera de homens e mulheres. Os brinquedos para meninos geralmente remetem à aventura, ao universo da ciência, à força, à coragem. Enquanto isso, para as meninas, há uma reprodução do universo materno, das atividades caseiras, da vaidade e da feminilidade.

Nesse sentido, Raquel Funari ${ }^{15}$ apresenta a preocupação entre a forma como meninos e meninas do sexto ano compreendem o Egito antigo. É possível perceber que as percepções femininas e masculinas, as sensibilidades e maneiras de conceber as relações sociais são muito distintas, mas fruto de uma construção da própria sociedade. Enquanto as meninas, segundo Funari, demonstraram interesse na figura de Cleópatra, os meninos se interessaram pelas pirâmides.

As fontes escolhidas exprimem essas questões, já que no caso do brinquedo "Múmias do Egito", apesar de não estar especificado o

\footnotetext{
${ }^{14}$ MORIN, E. Cultura de massas no século XX: o espírito do tempo. V.1. Rio de Janeiro: Forense-Universitária, 1975, p. 09.

${ }^{15}$ FUNARI, R.S. Imagens....
} 
público a que se destina, a descrição diz: "Ideal para pequenos faraós”. É possível perceber implícito o interesse que busca fomentar nos meninos, que conforme apontado acima por Raquel Funari, fascinam-se pelo mistério do Egito. Enquanto isso, as bonecas Barbie e Susie, ao longo de suas longas trajetórias, dedicadas ao público feminino, refletem ideais de beleza construídos pela sociedade. Nesse sentido, a escolha de incorporar a figura de Cleópatra à Barbie está ligada a noção de ícone de beleza que os discursos construíram a respeito da enigmática rainha do Egito. As outras duas bonecas que o estudo tomou como fontes, são também representações da beleza, do poder e do exotismo dos egípcios.

A partir das reflexões apresentadas, a pesquisa insere fontes inéditas no campo de estudo da Egiptomania no Brasil, e apresenta uma relação dessas com os papéis de gênero ligados a padrões culturais construídos. Padrões não relacionados somente às questões de gêneros, mas às visões de mundo e de relação com o passado, principalmente oriental - “construído” pelo presente ocidental. 